\title{
Research on the Dynamic Mechanism of Urbanization Based on Synergetics-A Case of Jiangxi Province of China
}

\author{
Da-jin $\mathrm{Yu}^{*}$
}

Department of Mathematics and Quantitative Economics, School of Information and Management, Jiangxi University of Finance and Economics, Jiangxi, 330032, China

\begin{abstract}
Urbanization is one of the most important phenomena of economy and society, which is the only way that must be passed to achieve modernization and the inevitable result of the synergetic collaborative evolution among the systems of socio-economic development. This paper analyzes the dynamic mechanism of urbanization based on synergetic, presents that the initial, fundamental and subsequent dynamic mechanism of promoting urbanization are the development of the primary, secondary, and tertiary industries, and then constructs a "pyramid" model of dynamic mechanism of urbanization based on Synergetic. On these bases, using co-integration analysis test, this paper conducts an empirical analysis of the relations between the level of urbanization and industrial structures of Jiangxi Province, China, and establish the relevant error correction model, and conducts Granger causality test. The results show that the level of urbanization develops collaboratively with the primary, secondary and tertiary industries, while Jiangxi's urbanization level increased $1 \%$, the GDP levels of the three industries will increase $3.18 \%, 5.33 \%$ and $6.08 \%$ respectively at the same time.
\end{abstract}

Keywords: Dynamic mechanism, industry, pyramid model, synergetics, urbanization.

\section{INTRODUCTION}

Urbanization is the integrated symbol of the level of economic development and social modernization, which also is the inevitable result of the synergetic evolution among the systems of socio-economic development. Since the reform and opening up, with the establishment of market economy and the gradual improvement, China's economy develop rapid, economic strength has markedly increased, and the level of urbanization has been greatly improved, rising from $17.92 \%$ in 1978 to $53.7 \%$ in 2013 . Due to differences in background and perspective, existing researches on the understanding of the concept of urbanization and characteristics are diversified. Related literatures showed that (Ma Baoping et al., 2008; Xu Xueqiang, et al., 2010; Jian Xinhua, et al, 2010; Yu Dajin, 2011), urbanization mainly represents a historical process that the rural population migrate to cities and towns and the profession of rural labor transfer to the urban secondary and tertiary industries, so the number and the scale of towns increasing with the development of social productivity, the progress of science and technology and the adjustment of industrial structure of a country or a region [14]. The process of urbanization is also a reflection of social change in the process of industrialization and modernization of countries (Gu Chaolin, 2005) [5].

The study about dynamic mechanism of urbanization is a hot issue in recent years. Henderson V (2003) studied the urbanization process and economic growth and found that the effects of urbanization rate on productivity growth is not significant. On the contrary, the rapid urbanization rate has negative impact on economic growth in some periods [6]. Lu Dadao et al. (2006) pointed out that regional economic development is the impetus of the development of urbanization dynamic mechanism [7]. Ahmad N et al. (2006) studied the significant impact of the economic growth on urbanization by the cross-sectional and time-series analysis of the data of 35 developing countries [8]. Xiong Jifeng (2007) verified the relationship between rural urbanization and the changes in per GDP and constructed dynamic mechanism index system of rural urbanization [9]. Taking China as an example, $\mathrm{Xu}$ Bing et al. (2008) carried out a case study of China how to reduce the gap of the development of regional urbanization [10]. Shen Liyin et al. (2012) put forward an alternative model of evaluation on urbanization sustainable development on the basis of analysis of urbanization and sustainable development capacity [12]. Wei Ye et al. (2013) studied the dynamic mechanism of Chinese urbanization development since 2000 combined with the panel data analysis, time series analysis and spatial analysis [13]. Some scholars selected some regions for empirical research, such as the $\mathrm{Li}$ Shitai et al. (2006) analyzed the pushing and hindering factors of dynamic mechanism of rural urbanization in Yantai city through building the structural model of the dynamic system [14]. Liu Lin et al. (2009) constructed the index system of various dynamic factors and analyzed the impact of various dynamic factors on urbanization in Xinjiang Province by using principal component analysis method [15]. Zhang Jie et al. (2010) analyzed dynamic mechanism of urbanization of five Northwestern Provinces by using panel data methods [11]. Ding Shengxi et al. (2013) studied the diversity, uniqueness of the dynamic mechanism of urbanization in surrounding regions of Qinghai Lake [16]. 
Scholars are paying more attentions to the issue of collaborative development promoting the urban development with the application and development of collaborative theory, and the studies on urbanization are also increasing. Through the analysis of the deep factors of constraining the county population migration and urbanization, Zhu Limeng (2006) discussed how to promote the collaborative among sustainable population, urbanization and economic development in the Poyang Lake region [17]. Eric J (2007) studied the factors affecting China's urbanization and the results of urbanization, pointed out the importance of policy interventions [18]. Lv Wenming et al. (2007) analyzed demonstrated that urbanization and industrialization must collaborative develop and put forward the countermeasures on urbanization scientific development in Hunan Province, China [19]. Chen Xiwen (2011) pointed out that industrialization and urbanization should make greater contributions to solve the "three rural" issue [20]. Sun Changqing (2012) analyzed the collaborative development of urbanization, industrialization and financial based on VAR model as a case of the Central Plains Economic Zone [21]. Hu Zhenya et al. (2012) proposed collaborative mechanisms of technological innovation, industrialization and urbanization by using a combination of quantitative and qualitative methods [22]. Zhong Jiayu et al. (2012) designed the mode and path of collaborative development of the small tour towns [23].

From the above analysis, it is not difficult to find that the studies of the dynamic mechanism of urbanization mostly stayed in the level of index system established. There are few research works about collaborative relation between the GDP of Primary, Secondary and Tertiary Industries and the level of urbanization. Based on the existing literature and collaboration theory, this paper studies the dynamic mechanism of urbanization, establish the relevant error correction model, conducts an empirical analysis of the relations between the level of urbanization and industrial structures of Jiangxi Province, and estimates and tests the collaborative relation between the GDP of Primary, Secondary and Tertiary Industries and the level of urbanization of Jiangxi.

\section{THE "PYRAMID" MODEL FOR DYNAMIC MECHANISM OF URBANIZATION BASED ON SYNERGETIC}

Synergetic is an emerging discipline of researching common feature of different things and synergy mechanisms, which was founded by Hermann Haken in 1977. There exist a variety of systems in objective world. Despite the different properties of these systems, there is an interaction and mutual cooperation relationship, which is a stable system, and its subsystems act and move orderly according to a certain synergy manner. Synergetic make the system consisted of the subsystems as the research object, the whole system will eventually form an orderly whole state through the interaction between these subsystems.

History of the development of regional urbanization in a sense is the history of co-evolutionary between regions and each intra-regional subsystem. In the initial stage of urbanization, regional agricultural and industrial systems developed collaboratively through self-organization, self-learning and self-evolution. Continuous improvement of the level of agricultural production and the growing social division of labor, more and more people come out from agricultural labor, which result in the forming of the town. It can be said that the urbanization is the product of rural economy to a certain stage. The level of development of rural economy is the basis of rural urbanization. So the development of primary industry can be taken as the initial motivation mechanism for promoting the urbanization. When primary industry develops to a certain stage, better production tools are demanded which promote the rise and continuous developing of secondary industry. The co-evolution of primary and secondary industries, then a large number of surplus agricultural labors begin to transfer to the industry. The industrialization is the precursor of urbanization. Industrialization provides the material basis for urbanization, and supports the development of urbanization. Therefore the development of secondary industry can be taken as the fundamental dynamic mechanism to promote urbanization. The cooperative evolution of agriculture and industrialization leads to further changes in the industrial structure. The rise and growth of the tertiary industry facilitates the industrial structure to high grade. When the evolution of agriculture and industrialization get to a higher stage, the leading role in urbanization process will be transferred from secondary industry to secondary and tertiary industries both gradually. So the tertiary industry can be taken as a subsequent dynamic mechanism of promoting urbanization. According to the above analysis, the "pyramid" model for dynamic mechanism of urbanization based on Synergetic can be constructed and shown as Fig. (1).

The development of regional urbanization shows that the dialectical relationship of the interdependence, mutual restraint and causal exists among the three industries in the aspect of increasing urbanization. That is to say, it is collaborative action of the three dynamic mechanisms of urbanization development. The relevant detailed analysis will be further explained in the fourth part of this paper.

\section{EMPIRICAL ANALYSIS OF THE RELATION BE- TWEEN THE LEVEL OF URBANIZATION AND IN- DUSTRIAL STRUCTURES OF JIANGXI, CHINA}

Jiangxi continues to accelerate the pace of urban construction with fast economic growth since the reform and opening up. Rural surplus labor keeps shifting into urban areas and gives a strong push to the urbanization process, which improves urbanization level steadily and stimulates the sound rapid development of Jiangxi economy and society. According to survey, the provincial urbanization level had been increased from $16.75 \%$ in 1978 to $48.87 \%$ in 2013 , with a rising rate of $32.12 \%$ in 34 years. Meanwhile, the primary industry, the secondary industry and the tertiary industry developed synergistically and GDP had also been improved significantly.

\subsection{Choice of Data and Variables}

This paper selects data from 2013 Jiangxi Statistics, defines urbanization level $x$ as the ratio of urban population in whole population, defines $y_{1}, y_{2}, y_{3}$ as the GDP in the primary, secondary and the tertiary industry, and analysis and 


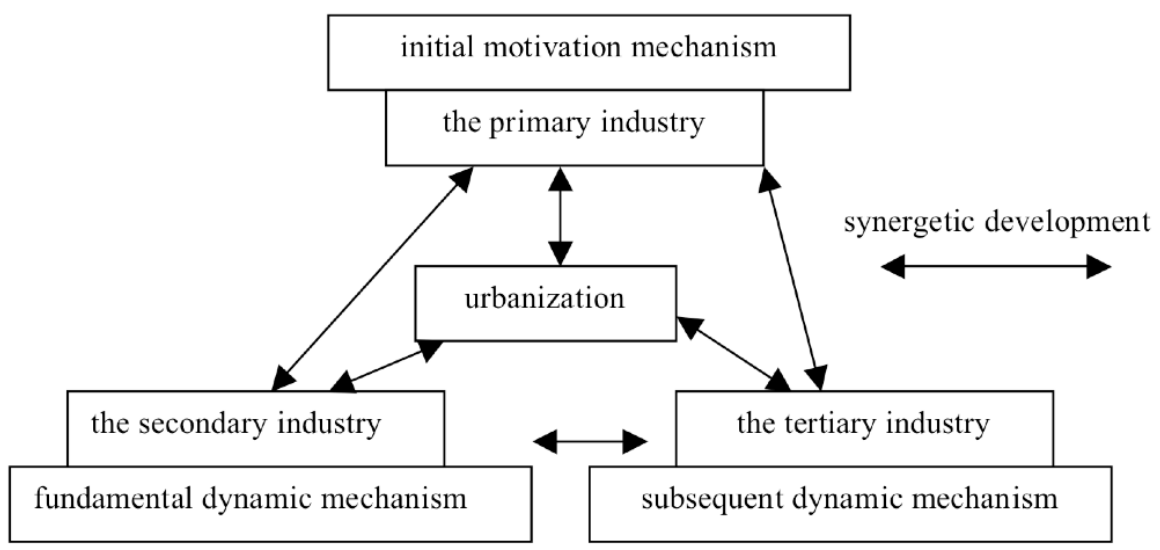

Fig. (1). The "pyramid" model for dynamic mechanism of urbanization based on Synergetics.

Table 1. The Correlation Matrix between the urbanization level and the GDP of the primary, secondary and tertiary industry in Jiangxi.

\begin{tabular}{|c|c|c|c|c|}
\hline & $\ln x$ & $\ln y_{1}$ & $\ln y_{2}$ & $\ln y_{3}$ \\
\hline \hline $\ln x$ & 1.000000 & 0.939871 & 0.978311 & 0.949610 \\
\hline $\ln y_{1}$ & 0.939871 & 1.000000 & 0.986524 & 0.997543 \\
\hline $\ln y_{2}$ & 0.978311 & 0.986524 & 1.000000 & 0.991030 \\
\hline $\ln y_{3}$ & 0.949610 & 0.997543 & 0.991030 & 1.000000 \\
\hline
\end{tabular}

test co-integration between $y_{1}, y_{2}, y_{3}$ and $x$. To eliminate the influence of heteroskedasticity, we calculate logarithm of original data as $\ln x, \ln y_{1}, \ln y_{2}, \ln y_{3}$, and the corresponding first order differences as $\Delta \ln x, \Delta \ln y_{1}, \Delta \ln y_{2}, \Delta \ln y_{3}$.

Calculating related coefficients between Jiangxi urbanization level and the GDP of the primary industry, the secondary industry and the tertiary industry, we get they are 0.94 , $0.98,0.95$ individually and were shown in Table $\mathbf{1}$. We find the relation is obvious.

\subsection{Test for Sequence Smoothness}

If the time sequences we considered have the same integration orders, and some linear combination has lowered the combined time sequences' integration order, these time sequences are described as having obvious co-integration. The proposal of co-integration conception has settled a theoretical foundation for finding equilibrium relation among unsmooth variables and constructed error-revision model with variables with co-integration relations.

The premise for co-integration analysis are the time sequences that be selected must be smooth. So the time sequences must be tested for smoothness before co-integration analysis. There are many methods for testing. One of them is to test its smoothness vaguely with the sequences' timing path graph. But such direct graphs can be misguiding so this method is not used regularly. The more precise and important method compared to the previous one is to test with statistics. The unit root test is a testing method using widely in statistics test. Currently there are various kinds of unit root tests, among which DF test and ADF test are most popular.
But when time sequences include obvious changing trend with time, DF test is likely to result in the problem of autocorrelation random distracters. Therefore this paper chooses ADF test. The original hypothesis of ADF test is time sequences which are not smooth, which means there exists unit root. Inversely, if time sequences are smooth, there is not exist unit root. Testing the time sequences and results are shown in Table 2.

It is clear from test results that sequences of $\ln x, \ln y_{1}, \ln y_{2}, \ln y_{3}$ accept the original hypothesis and are unsmooth in $10 \%$ confidence level. Sequences of $\Delta \ln x, \Delta \ln y_{1}, \Delta \ln y_{2}, \Delta \ln y_{3}$ reject the original hypothesis and are smooth. Thus we conclude $\ln x, \ln y_{1}, \ln y_{2}, \ln y_{3}$ are first order intergratedness sequences and further tests can be made.

\subsection{Co-integration Test and Error Revision Model}

It is clear that $\ln x, \ln y_{1}, \ln y_{2}, \ln y_{3}$ are unsmooth and their first differences are smooth form the results of unit root test, which fulfills premise for co-integration test and cointegration relation is possible. Following we carry out the ADF co-integration test for these sequences.

Firstly, we can get co-integration test equations between sequences by estimating linear combination of $\ln x, \ln y_{1}, \ln y_{2}$, $\ln y_{3}$ sequences with general least squares estimation method.

$$
\begin{aligned}
& \ln y_{1}=-4.8705+3.1816 \ln x, R^{2}=0.8735 ; \\
& \ln y_{2}=-10.5624+5.3260 \ln x, R^{2}=0.9621 ; \\
& \ln y_{3}=-11.3345+6.0849 \ln x, R^{2}=0.9179 .
\end{aligned}
$$


Table 2. The test results of ADF unit root.

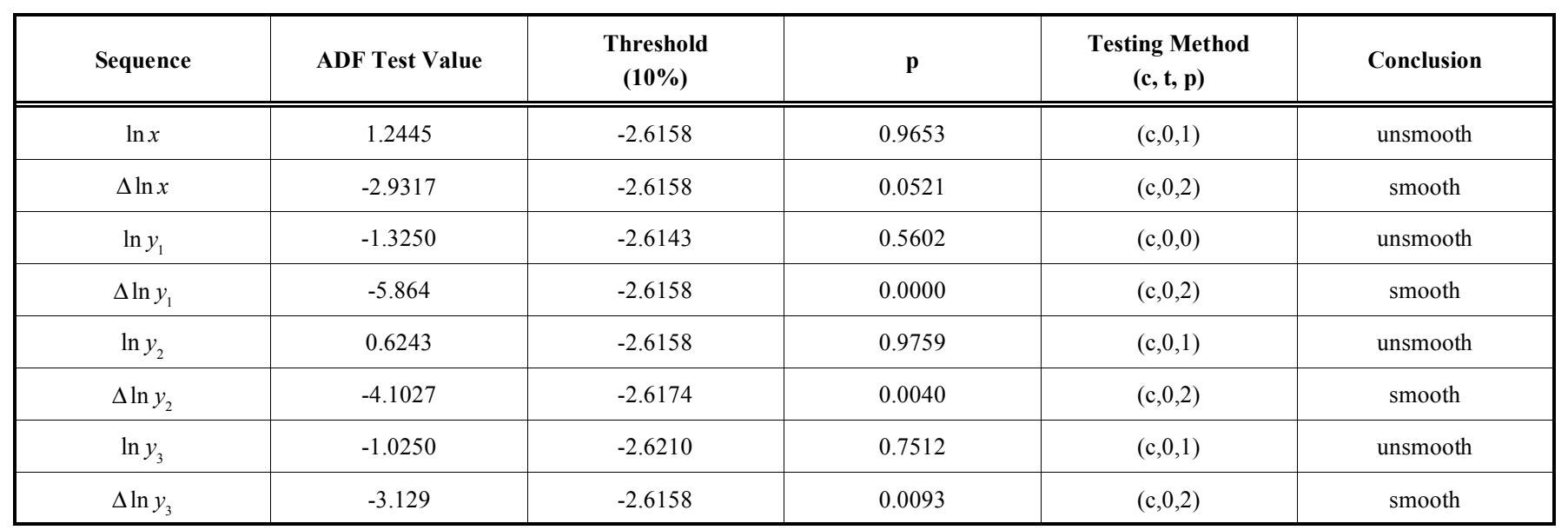

Table 3. The test results of ADF co-integration relationship.

\begin{tabular}{|c|c|c|c|c|}
\hline Sequence & ADF Test Value & $\begin{array}{c}\text { Threshold } \\
\mathbf{( 1 0 \% )}\end{array}$ & p & Conclusion \\
\hline \hline$\hat{u}_{1}$ & -4.3524 & -2.6158 & 0.0014 & smooth \\
\hline$\hat{u}_{2}$ & -3.3108 & -2.6158 & 0.0265 & smooth \\
\hline$\hat{u}_{3}$ & -2.6371 & -2.6158 & 0.0910 & smooth \\
\hline
\end{tabular}

$\Delta \ln y_{1}(-1)=0.5017 E C M 1+2.8169 \Delta \ln x+0.0863 \Delta \ln y_{1}(-2)-1.0989 \Delta \ln x(-1)$
$(0.0813)$
$(0.7295)$
(0.1243)
$(0.5912)$
[5.7810]
[3.6872]
[0.7006]
$[-1.861]$

$R^{2}=0.7625$

$\Delta \ln y_{2}(-1)=0.4631 E C M 2+2.1936 \Delta \ln x+0.3098 \Delta \ln y_{2}(-2)+0.2624 \Delta \ln x(-1)$
$(0.0591)$
$(0.5780)$
(0.0941)
$(0.4121)$
$[7.5630]$
[3.9713]
[3.0190]
[0.5933]

(2)

$R^{2}=0.8127$

$$
\begin{array}{rccc}
\left.\Delta \ln y_{3}(-1)=0.5016 E C M 3+2.6105 \Delta \ln x+0.2129 \Delta \ln y_{3}(-2)\right)+0.2607 \Delta \ln x(-1) \\
(0.0715) & (0.6980) & (0.1307) & (0.4275) \\
{[7.0253]} & {[3.6921]} & {[1.6578]} & {[0.6046]}
\end{array}
$$

$$
R^{2}=0.7831
$$

Perform unit root test for residuals of above cointegration formulas and get results as shown in Table $\mathbf{3}$.

According to Table $\mathbf{3}$, we know that $\hat{u}_{1}, \hat{u}_{2}, \hat{u}_{3}$ residuals reject original hypothesis and no unit roots exist, which means $\hat{u}_{1}, \hat{u}_{2}, \hat{u}_{3}$ are smooth under $10 \%$ confidence level. That means there exist co-integrated relation between $\ln y_{1}, \ln y_{2}, \ln y_{3}$ and $\ln x$. Additionally we can get for each $1 \%$ the urbanization level be increased, the GDP of the primary industry, the secondary industry and the tertiary industry will be increased $3.18 \%, 5.33 \%$ and $6.08 \%$ individually from its linear relation. We can conclude that the change of urbanization level has less influence on the GDP of the primary industry which mainly consists of agriculture relatively, medium influence on the GDP of the secondary industry which mainly consists of industry, and most influence on the GDP of the tertiary industry which mainly consists of services. But we also obvious find that GDP of the secondary and the tertiary industry have increased at almost a same speed. The urbanization level of Jiangxi is in a period of rapid rise and it's connected closely to the increase of GDPs of the secondary and the tertiary industry.

The long-run equilibrium residual can be obtained by regression equation between $\ln y_{1}, \ln y_{2}, \ln y_{3}$ and $\ln x$ :

$$
\begin{aligned}
& E C M 1=\ln y_{1}+4.8705-3.1816 \ln x \\
& E C M 2=\ln y_{2}+10.5624-5.3260 \ln x \\
& E C M 3=\ln y_{3}+11.3345-6.0849 \ln x
\end{aligned}
$$


The error revision model verifying the relation between urbanization level change and GDPs of three industries are shown in Equation (1)(2)(3), in which numbers in ( ) represents estimated standard error and number in [ ] means $t$ statistics.

Equation (1) means for Jiangxi Province, the GDP of the primary industry in last term are affected by urbanization level in the last and the current term and GDP of the primary industry in the last and before the last term. Equation (2) means the GDP of the secondary industry in last term are affected by urbanization level in the last and the current term, and GDP of the secondary industry in last term and before the last term. Equation (3) means the GDP of the tertiary industry in last term is affected by urbanization level in the last and the current term, and GDP of the tertiary industry in the last term and before the last term. In a word, the GDPs of the three industries are in long-run equilibrium relation with urbanization level of Jiangxi Province.

\section{COLLABORATIVE ANALYSIS OF THE DYNAMIC MECHANISM OF JIANGXI URBANIZATION}

We already know there is long-run equilibrium relation between variables, but a synergy relation may also be possible. In order to give better explanations of dynamic mechanism, a testimony is given with Granger causality test. Table 4 gives a vivid description of the synergy between the three industries.

Table 4 shows that, at $10 \%$ confidence level, the primary industry is the Granger cause of the secondary industry when the lag order is 2 , which means the development of the primary industry stimulates the secondary industry. When the lag order is 1 or 2 , the secondary industry is the Granger reason for the primary industry, which means the development of the secondary industry stimulates the primary industry. When the lag order is 2, 3 or 4, the tertiary industry is the Granger reason for the secondary industry, which means the development of the tertiary industry stimulates the secondary industry. When the lag order equals $1,2,3$ or 4 , the secondary industry is the Granger reason for the tertiary industry, which means the development of the secondary industry stimulates the tertiary industry. When the lag order is 4 , the primary industry is the Granger reason for the tertiary industry, which means the development of the primary industry stimulates the tertiary industry. Therefore the primary industry and the secondary industry interact and promotes jointly, which is the same as the tertiary industry and the secondary industry. In other words, the three industries are in synergy development. This reflect a phenomenon that one industry's economic activity appears in another industry, usually we called industrial integration. For example, the integration between the secondary and the tertiary industry are shown mainly in following aspects: (1) In certain manufacturing area, more software system for control, operation and application are involved, making the whole process automated. (2) In the whole manufacturing sector, the ratio of services is increasing, as the increase of services in traditional manufacturing focusing in products sales and management. The effect of such integration is obvious, utilization of automation increases manufacturing efficiency and the output capacity of the secondary industry. In addition, the increase of services has ameliorated client relationship and expanded operating space. The promotion of after-sale services stimulates the secondary industry. Conversely, the development of the secondary industry produces more profit which means more funds in improving automation and services, which promotes the tertiary industry.

\section{CONCLUSION AND POLICY RECOMMENDA- TIONS}

\subsection{Conclusion}

This paper analyzes the dynamic mechanism of urbanization, maintains the idea that the initial, fundamental and subsequent dynamic mechanism driving modernization are the development of the primary, secondary and tertiary industries respectively, and constructs the "pyramid" model for urbanization dynamic mechanism based on Synergetic. On these bases, employing co-integration analysis of previous achievements, this paper establishes relevant error correction models for GDP of primary, secondary and tertiary industries and urbanization development in Jiangxi, then conduct the Granger causality test, and obtain the conclusions:

Firstly, according to the correlation coefficient between the urbanization of Jiangxi and the GDP of primary, secondary and tertiary industries is $0.94,0.98$ and 0.95 , showing that there is a close positive relationship between them. In other words, the improvement of GDP for primary, secondary and tertiary industries promote the development of urbanization in Jiangxi province.

Secondly, as Jiangxi's urbanization level increased 1\%, the GDP levels of the three industries will respective in-

Table 4. The results of Granger test of causality.

\begin{tabular}{|c|c|c|c|c|}
\hline $\begin{array}{l}\text { Original Hypothesis } \\
\text { Lag Order }\end{array}$ & $p=1$ & $p=2$ & $p=3$ & $p=4$ \\
\hline$y_{2}$ is not the Granger reason for $y_{1}$ & 0.0926 & 0.0381 & 0.1291 & 0.2831 \\
\hline$y_{1}$ is not the Granger reason for $y_{2}$ & 0.2529 & 0.0208 & 0.3719 & 0.5764 \\
\hline$y_{3}$ is not the Granger reason for $y_{2}$ & 0.4986 & 0.00000000 & 0.0000007 & 0.00002 \\
\hline$y_{3}$ is not the Granger reason for $y_{1}$ & 0.3204 & 0.1387 & 0.2812 & 0.3638 \\
\hline$y_{1}$ is not the Granger reason for $y_{3}$ & 0.6245 & 0.3911 & 0.7437 & 0.0561 \\
\hline
\end{tabular}


crease $3.18 \%, 5.33 \%$ and $6.08 \%$ at the same time. In other words, the change of the level of urbanization in Jiangxi province has less impact on GDP for agriculture-based primary industry, while the influence on GDP for the secondary industrial-based industry and the service-oriented tertiary industry is larger.

Thirdly, the synergistic reaction of dynamic mechanism explained in further that there is a dialectical relation of interdependence, mutual restriction, and reciprocal causation among the primary, secondary and tertiary industries. The primary industry is the foundation of the development of the secondary and the tertiary industry, when the agricultural develop to a certain extent, surplus labor will begin to transfer to the secondary and the tertiary industry, which promoting the development of the secondary and the tertiary industry, and also enhance the level of urbanization. The development of the second industry has brought a strong driving force for the development of the primary and the tertiary industry while the development of the tertiary industry has played a significant role in the development of the primary and secondary industry. Because the development of the secondary and tertiary industries is largely service for other industries or improve production efficiency and expand the scale of production itself. These will promote the professional, social production, improve output efficiency, reduce transaction costs, thereby enhance the potential for further development of urbanization.

\subsection{Policy Recommendations}

The development of urbanization needs the coordinated development of primary, secondary and tertiary industries for Jiangxi province. Without the development of the primary industry, the secondary industry can't have a better development. On the contrary, when the tertiary develop to a certain extent, it also can promote the development of the primary and secondary industries. Developing the tertiary industry is neither to develop the primary and secondary industries after the tertiary industry has a good development nor to develop the tertiary industry by weakening the primary and secondary industries. The primary, secondary and tertiary industries should develop collaboratively.

The aspect of the primary industry. Ecological agriculture and modern agriculture is not only a big trend in agricultural development, but also an inevitable choice to the development of the society. The ultimate goal of urbanization is the ecological urbanization. Jiangxi province should be combined with their own reality, and take effective measures to promote the rapid and healthy development of ecological agriculture. We should develop diversified agriculture and take the opportunity of the new rural construction, integrate the existing resources, change the traditional mode of grain monoculture, to achieve the diversified development of fruits, vegetables, and poultry. Furthermore, a number of good infrastructure, high-tech, large-scale agricultural production and processing base should be cultivated, implementing the strategy of agricultural scale, modernization and brand, to promote the development of agriculture fast, efficient and high quality.

The aspect of the secondary industry. As the main driving force of urbanization is the secondary industry, Jiangxi province should make great efforts to undertake industrial movement, improve the ability of technological innovation based on the existing industrial parks, and promote economic growth from depending resource to relying on science and technology. Moreover, we should promote the integration of information and industrialization, using information to promote industrialization and promoting the information with industrialization. We should take the opportunity of the national strategy for building the Poyang Lake Ecological Zone to improve the regulation of long-term mechanism of energy conservation, develop low-carbon economy, circular economy, energy conservation and environmental protection industries, and then promote the new industrialization process.

The aspect of the tertiary industry. The development of the tertiary industry is backward in Jiangxi province, the level of service industry is low and the competitiveness is not strong. In order to solve this problem, Jiangxi province should rely on its advantages and develop modern service industry vigorously. There are other suggestions: (1)Supporting emerging service industries, accelerate the reform of the employment system and the household registration system, focus on the development of labor-intensive services, create more opportunities for employment and reemployment, attract more people to come to town. (2)Increasing the institutional innovation, strengthen the integration of tourism resources, strengthen regional cooperation, optimize the tourism brand, and make the ecological tourism bigger and stronger. (3Relying on the traffic arteries and an important hub for the region, play the shipping role of Yangtze River and Poyang Lake, accelerate the construction of logistics hub in Nanchang central, and extend the logistics platform. (4)Accelerating the innovation of investment and financing system, improve and perfect the financial service system further.

\section{CONFLICT OF INTEREST}

The author confirms that this article content has no conflict of interest.

\section{ACKNOWLEDGEMENTS}

Funding support for this research were provided by the National Social Sciences Fund Project "Research on the measurement and promoting of urbanization quality in undeveloped areas (13BGL010)", and the Science and Technology Project of Education Department in Jiangxi "Research on the measurement of development distance of regional eco-urbanization-case of Jiangxi (GJJ13299)".

\section{REFERENCES}

[1] B. P. Ma, and G. S. Zhang, Outline of Urbanization with Chinese Characteristics, Economic Science Publish, 2008.

[2] X. Xu, and B. Deng, Urban Geography, Higher Education Press, 2010.

[3] X. Jian, and K. Huang, "Empirical analysis and forecast of the level and speed of urbanization in China," Economic Research, (in Chinese), vol. 45, no. 3, pp. 28-39, 2010.

[4] D. Yu, Research on the Development of New Urbanization in Poyang Lake Eco-economic Zone Based on Conservation Culture, Economic Science Publish, (in Chinese) 2011.

[5] V. Henderson, "The urbanization process and economic growth: The so-what question," Journal of Economic Growth, vol. 8, no. 8, pp. 47-71, 2003. 
[6] C. Gu, Urban System Planning: Theory Examples, China Architecture \& Building Press, (in Chinese), 2005.

[7] D. Lu, S. Yao, and H. Liu, China Regional Development Report in 2006-Urbanization Process and Spatial Expansion, The Commercial Press, (in Chinese) 2007.

[8] A. N. Abdel-Rahman, M. R. Safarzadeh, and M. B. Bottomley. "Economic growth and urbanization: a cross-section and time-series analysis of thirty-five developing countries," RISEC, vol. 53, no. 3, pp. 334-348, 2006.

[9] J. Xiong, "Compared the Dynamic Mechanism of rural Urbanization Between Zhejiang and the Central Region," China Social Sciences Publishing House, (in Chinese) 2007.

[10] B. Xu, and W. Junzo, "Identification of regional urbanization gap: evidence of China," Journal of Modeling in Management. vol. 3, no. 1, pp. 7-25, (in Chinese) 2008.

[11] J. Zhang and X. Gong, "Motive mechanism of urbanization on in Northwest: based on the empirical panel data," Journal of Capital University of Economics and Business, (in Chinese), vol. 12, no. 5, pp. 81-101, 2010.

[12] L. Shen, Y. Peng, X. Zhang, and Y. Wu, "An alternative model for evaluating sustainable urbanization," Cities, vol. 29, pp. 32-39, 2012.

[13] Y. Wei, C. Xiu, P. Sun, "Dynamic mechanism of urbanization in China since 2000," Geographical Research, (in Chinese), vol. 32, no. 9, pp. 1679-1687, 2013.

[14] S. Li, and F. Sun, "The exploration of ways of developing the industrialization of ecological agriculture," Economic Geography, (in Chinese), vol. 26, no. 5, pp. 815-818, 2006.

[15] Liu Lin, and Xinshu Gong, "Research on dynamic mechanism of urbanization in Xinjiang based on principal component analysis,"
FuJian Tribune, (in Chinese), vol. 29, no. 2, pp. 34-36, 2009.

[16] S. Ding, and X. Wang, "Analysis on urbanization dynamical mechanisms of minority nationality regions in Qinghai-Tibet Plateau: take the region around Qinghai Lake as example," Areal Research and Development, (in Chinese), vol. 31, no. 1, pp. 65-69, 2012.

[17] L. Zhu, "Thoughts on the relationship among such factors as population, urbanization and sustainable development of the Poyang Lake ring counties," Contemporary Finance \& Economics, (in Chinese), vol. 27, no. 8, pp. 84-89, 2006.

[18] E. J. Heikkila, "Three questions regarding urbanization in China," Journal of Planning Education and Research, vol. 27, pp. 65-81, 2007.

[19] W. Lu, and H. Liu, "The study on regional difference and countermeasure of coordinated development in Hunan Province," Economic Geography, (in Chinese), vol. 27, no. 3, pp. 467-469, 2007.

[20] X. Chen, "Urbanization should make greater contributions to solve the three rural issues," Economic Research Journal, (in Chinese), vol. 46, no. 10, pp. 8-10, 2011.

[21] C. Sun, "An analysis on the relationship between urbanization, industrialization and financial development-a case study of the Central Plains Economic Zone," Economic Survey, (in Chinese), vol. 29, no. 6, pp.17-21, 2012.

[22] Hu Zhen-ya, and Rong Wang, "Research of technological innovation and joint development," Scientific Management Research, (in Chinese), vol. 32, no. 6, pp. 5-8, 2012.

[23] J. Zhong, and S. Liu, "Development countermeasures of small tourism towns based on synergetics: taking Hunan Province as an example," Economic Geography, (in Chinese), vol. 32, no. 7, pp. 159-164, 2012.

(C) Da-jin Yu; Licensee Bentham Open.

This is an open access article licensed under the terms of the Creative Commons Attribution Non-Commercial License (http://creativecommons.org/licenses/by-nc/3.0/) which permits unrestricted, non-commercial use, distribution and reproduction in any medium, provided the work is properly cited. 